\title{
CONTRASTE DE ESTILOS ESTRUTURAIS E METAMÓRFICOS NA FAIXA DOBRADA SERGIPANA
}

\author{
EMANUEL FERRAZ JARDIM DE SÁ*; JEAN-MICHEL LEGRAND** \\ P PETER CHRISTIAN HACKSPACHER*
}

\begin{abstract}
The Sergipe fold belt can be divided in two segments. The metasediments in the southern one (Miaba and Vaza Barris groups) were deformed mostly by a WNW-trending folding phase associated with high-angle thrusts $\left(F_{1}\right)$. The metamorphism is monophasic, of greenschist or prehnite-pumpellyite facies and probably of intermediate pressure type. Later deformation episodes include kinks, crenulation $\left(\dot{F}_{2}\right)$ and WNW transcurrent shear zones with steep plunging folds $\left(F_{3}\right)$ :

The supracrustals in the northern segment (Macurure Group) were deformed by three phases of macroscopic folds. The first one $\left(F_{1}\right)$ is characterized by tight to isoclinal, originally.recumbent and transposed folds with southern vergence. A metamorphic event ranged from greenschist to high amphibolite facies (reaching sillimanite and anatexis isograds to the North), probably in a low pressure regime $\left(M_{1}\right)$. A second phase was responsible for SE-verging, closed to tight, overturned or inclined folds $\left(F_{2}\right)$. A new metamorphic recrystallization episode $\left(M_{2}\right)$ proceeded from greenschist to amphibolite facies, with kyanite or andaluzite present. A third deformation event $\left(F_{3}\right)$ can be detected, with northern-verning inclined folds. The associated metamorphism reached the kyanite isograd. Small and large scale interference patterns were defined by superimposition of the different phases.

Structural correlations across the two segments suggest that the main folding in the south $-\left(F_{1}\right)_{\mathrm{S}}$ - can be equated with the third one to the north $-\left(F_{3}\right)_{\mathrm{N}}$. The southern metasediments have been correlated with the upper Proterozoic Bambui Group based on lithological grounds. A few radiometric dates support the assumption of a middle or lower Proterozoic age for the northern supracrustals, and their similarities with the other schist belts in the Northeast region are striking. Although a coeval evolution cannot be excluded at this stage, we favour the interpretation that the northern segment behaved as a basement unit, and was rejuvenated during the Brasiliano event, characterized by the development of an ensialic fold beld represented by the southern segment.
\end{abstract}

INTRODUÇÃO A faixa dobrada Sergipana perfaz o limite nordeste do Craton São Francisco, tendo sua evolução sido reportada ao Ciclo Brasiliano (Almeida, 1967, vide carta geológica ao milionésimo, folha Aracaju; e Bruni, 1976). Uma compilação e síntese dos trabalhos nesta faixa foram feitas por Brito Neves et al. (1977a).

Estudos de âmbito regional foram iniciados nesta província por Humphrey e Allard (1969) na parte sul desta faixa (Sergipe). Um prisma de metassedimentos foi dividido em dois grupos - Miaba e Vaza Barris -, representando seqüências mio e eugeossinclinais, separadas por discordância e um extenso empurrão. A estrutura foi descrita em termos simples, com grande anticlinal revirado ("Pinhăo"), empurrado sobre a sequência molássica (o Grupo Estância) a sul. Ao norte deste dominio, os autores reconheceram um complexo batolítico semi-aflorảnte, circundado por cornubianitos. Metassedimentos a oeste da bacia cretácea do Tucano - os grupos Macururé, Canudos e Bambuí, estudados por Barbosa (1970) e Jordan (1968 e 1971) - foram correlacionados com os equivalentes em Sergipe, comprovando a extensão para oeste da faixa.

Um zoneamento geotectônico desta unidade foi traçado por Santos e Silva Filho (1975), reconhecendo o domínio miogeossinclinal na região sergipana enquanto os metassedimentos ao norte, e além do Rio São Fran- cisco (Alagoas), corresponderiam ao domínio eugeossinclinal. Neste último, as rochas mètamórficas foram corretamente identificadas como do tipo regional, com um dobramento mais enérgico e empurróes para o sul. Um zoneamento análogo foi proposto por Brito Neves (1975) e Mello et al. (1977); estes últimos descreveram o metamorfismo da faixa como do tipo Barroviano.

Brito Neves et al. (1977b) enfatizaram uma vergência centrífuga na faixa, com os segmentos sergipano e alagoano divergindo a partir de uma faixa central com intrusð̃es graníticas ao sul do São Francisco. Um modelo preliminar de placas tectônicas foi proposto para explicar a faixa, mediante o choque do Craton Săo Francisco, ao sul, com o "Maciço Pernambuco-Alagoas" ao norte. Silva Filho et al. (1977 e 1978) redefiniram a estratigrafia e descreveram a estrutura e o metamorfismo da faixa com base em mapeamento sistemático. Na região sul foram identificadas diversas falhas de empurrão. Os traços de foliação e o comportamento dos quartzitos nos mapas são indicativos de crescente complexidade estrutural em direção norte. Nesse mesmo sentido sucedem-se as zonas metamórficas da biotita, granada, cianita-estaurolita e andaluzita, e sillimanita. O zoneamento geotectônico utilizado é análogo aos anteriores, assinalando-se a presença de um "complexo ofiolítico" na regiåo eugeossinclinal. Um novo modelo de evolução foi proposto, com margens ativas na borda

* Departamento de Geologia, Centro de Ciências Exatas, Universidade Federal do Rio Grande do Norte, Campus Universitário, CEP 59000, Natal, RN 


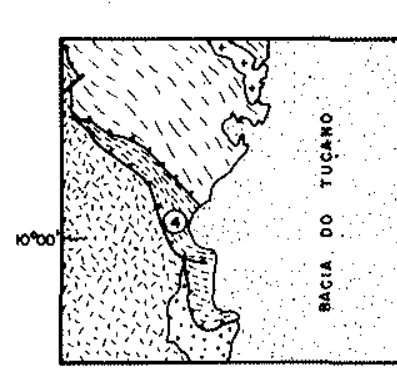

(2) arapiraca (2) eatalha (3) Can (5) Cel. joä́o sa' (6) feira mova (7) gaharu (a) gracho cafdoso

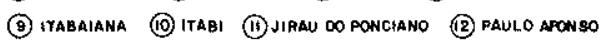
(13) PINHào (14) Propala' (1B) SIMÃ̃o DIAS (1B) TRAIPU (17) MARITÁ

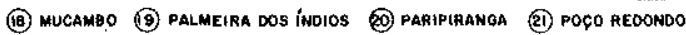
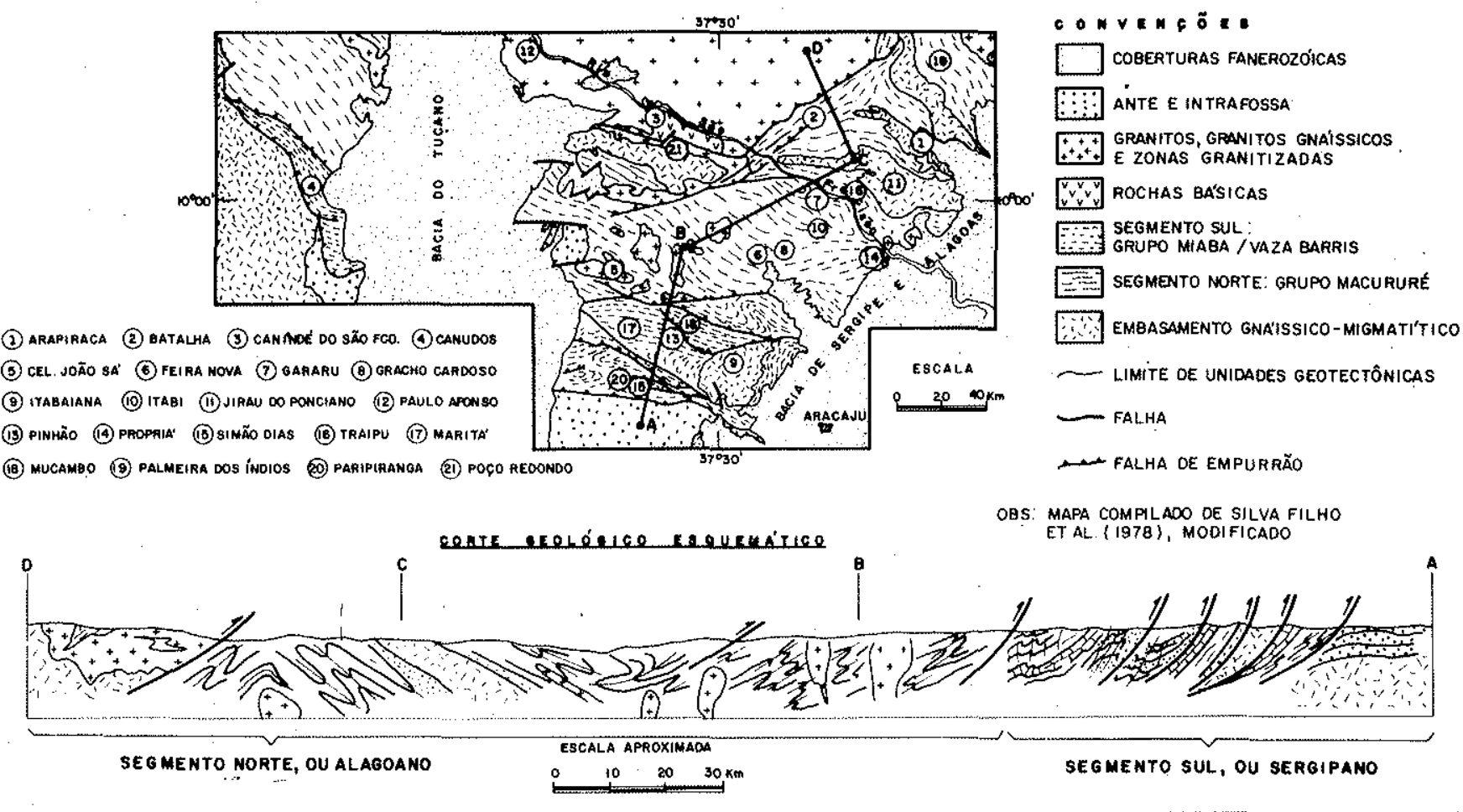

Figura 1 - Esboço geológico da Faixa Sergipana

de cada núcleo cratônico, sendo a sergipana mais antiga, e finalizando com o choque das placas.

Neste trabalho, procuramos avançar na caracterização estrutural e metamórfica dos dois segmentos da faixa, comparando-os e discutindo as implicações dos dados no que toca à evolução geológica regional. É dada ênfase ao estudo das estruturas dúcteis relacionadas à deformação orogênica. Embora seja feita breve referência, o estudo de estruturas do embasamento está fora do espaço deste trabalho. A metodologia adotada foi a de realizar seções transversais ao longo da faixa, estudando em detalhe a maior parte de seus afloramentos. Neste caso, os caminhamentos são compatíveis com mapeamentos entre 1:50 é 1:25 000, embora não tenham a sistematização dos mesmos. Foram estudadas petrograficamente 32 amostras ao longo do trecho mais largo da faixa.

\section{COMPONENTES LITOESTRATIGRÁFICOS DA}

FAIXA Segundo os modelos estratigráficos aceitos na região (sumarizados e discutidos por Bruni, op. cit., Brito Neves et. al. op. cit., e Silva Filho et al., op. cit.), o segmento sul foi inicialmente preenchido por uma sequiência quartzítica descontínua, passando a metagrauvacas, metapelitos e metacarbonatos (Grupo Miaba). Este pacote seria capeado por metagrauvacas seixosas, filitos, metacarbonatos, ardósias, metassiltitos e metarenitos arcosianos e grauváquicos (Grupo Vaza Barris) (Fig. 1).

No segmento norte, o Grupo Macururé é predominantemente composto de micaxistos, metagrauvacas xistosas e filitos, com quartzitos e gnaisses quartzo-feldspáticos e biotíticos na base (estruturalmente), e intercalações menores de mármore, anfibolitos, clorita xistos, calcossilicáticas, etc. Ao contrário do segmento sul, as feiçoes estruturais e metamórficas impediram a formulação de uma coluna estratigráfica neste domínio. Um importante corpo de (meta) gabros e diabásios, associados a metabasaltos e metassedimentos, ocorre na região de Canindé do São Francisco e Poço Redondo (SE). Migmatitos ocorrem na regiâo alagoana deste domínio.

Os litotipos dos grupos Miaba-Vaza Barris representam uma típica seqüência de plataforma (shelf). As metagrauvacas seixosas gradam a ardósias com o desaparecimento dos seixos e diminuição do tamanho de grão (quartzo, principalmente) na matriz. A interpretação de ciclos turbidíticos, aventada por Silva Filho et al. (op. cit.), parece-nos adequada. No grupo Macururé, Brito Neves et al. (op. cit.) reportaram a ocorrência de wild flysch na região de Gracho Cardoso (SE). Trata-se de um metaconglomerado com matriz metapelítica e seixos de filitos e ardósias de composição similar. Tanto a matriz como os seixos estão deformados pelas estruturas mais antigas, a fábrica sendo contínua de um a outro em diversos exemplos, ou restrita aos fragmentos e discordante da matriz. Essas características são análogas às de olitostromas (Elter e Trevisan, 1973) e deixam bem estabelecida uma sedimentação tipo flysch sinorogênico, pelo menos para uma parte do Grupo Macururé.

Por fim, mencionamos os sedimentos plataformais (Grupo Estância) e molássicos (Formação Palmares) de 
antefossa, ao sul da área do Vaza Barris, bem como uma intrafossa molássica (Formação Juá) no segmento norte, descritos por Silva Filho et al. (op. cit.) e Mello (1977 e 1978).

\section{O ESTILO ESTRUTURAL}

O SEGMENTO SUL: OS GRUPOS MIABA E VAZA $B A R R I S$ A estrutura neste domínio pode ser descrita como relativamente simples e está representada na Fig. 2.

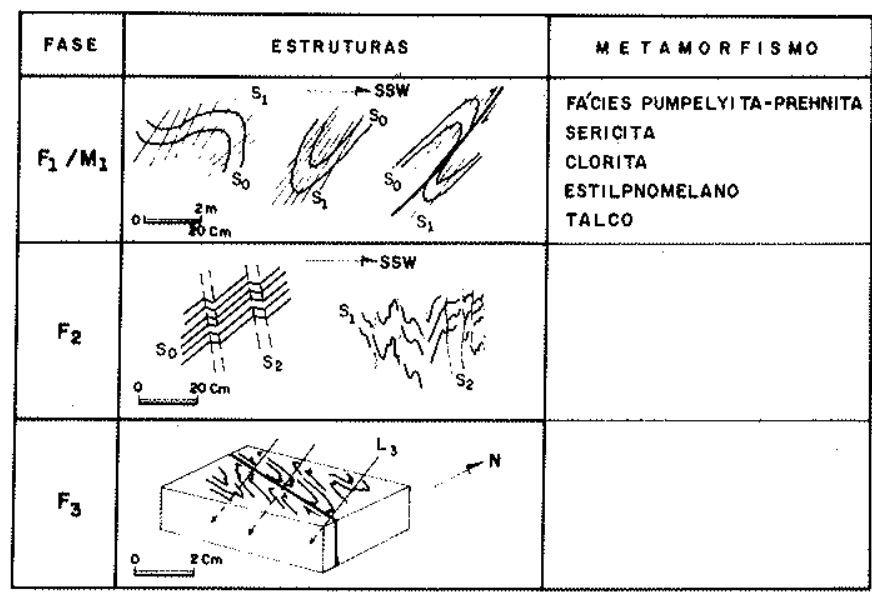

Figura 2 - Estruturas e metamorfismo no segmento sul da Faixa Sergipana

$F_{1}$ : Esta deformação é caracterizada por macro e minidobras com plano axial de mergulho forte para $\mathrm{N}$ NNE (vergência sul), ou subvertical, e eixo com caimento suave predominantemente para WNW. Afetam a estratificação $\left(S_{0}\right)$ em estilo variável, de isoclinais a fecha* das, configurando tipos invertidos e inclinados, classes $1 \mathrm{C}$ a 3 . As charneiras são curvas. Essa variação reflete uma deformação heterogênea, ora em função da litologia dobrada, ora do posicionamento geográfico (dobras apertadas são mais desenvolvidas a sul). Em função da competência e da heterogeneidade do material, as minidobras são mais bem desenvolvidas nos carbonatos e metapelitos acamados.

$F_{l}$ : Produziu clivagem ardosiana em metapelitos e calcários filitosos, às vezes acompanhada de diferenciação metamórfica (leitos quałtzosos alternantes com micáceos, com poucos milímetros de espessura, paralelos à clivagem). Nos metacarbonatos maciços, a clivagem é de fratura. Esta foliação $\left(S_{1}\right)$ normalmente se dispõe em leque, mais evidente nos exemplos mais abertos. Dominam os mergulhos para o norte (com mais de $60^{\circ}$ ), mas ao norte do Rio Vaza Barris são também encontrados mergulhos fortes para o sul (mais de $70^{\circ}$ ). Lineações $L_{1}$ incluem eixos de minidobras $\left(B_{1}\right)$ e interseçðes $S_{\mathrm{o}} / S_{1}$, com predomínio de mergulhos suaves (menos de $15^{\circ}$ ) para WNW.

Nas metagrauvacas, $S_{1}$ é defletida e rotaciona seixos cujo eixo maior, subvertical, está contido neste plano e é correlacionável ao eixo $X$ do elipsóide de deformaçăo.
O estiramento dos seixos é moderado, com a razão $X / Z$ variando de 2:1 a 3:1. Dobramento de veios de quartzo e carbonato, constituindo segregações precoces no metamorfismo, e a variação de estilos sugerem que $F_{1}$ é uma deformação progressiva heterogênea.

Com o progressivo afinamento de seus flancos invertidos, as dobras $F_{1}$ podem evoluir até falhas inversas/empurrões, subparalelas a $S_{1}$, desenvolvidas internamente ou no contato entre unidades litológicas (metapelitos versus metacarbonatos, por exemplo). Essas falhas são acompanhadas por intensa venulação de quartzo e provocam repetição e espessamento das camadas. $\mathrm{Na}$ região de Simão Dias, a intercalação na seqüência supracrustal, de uma cunha de gnaisses e migmatitos do embasamento, é outro exemplo da atuaçåo dessas falhas inversas. Seu contato sul é caracterizado por milonitos e blastomilonitos, com recristalização de biotita e epídoto, implicando condições $P T$ mais severas que nos metassedimentos adjacentes, caracterizando uma falha profunda. As demais parecem restringir-se ao nivel da cobertura. O desenvolvimento cronológico exato dessas falhas não pôde ser determinado mas parece haver uma variação temporal-geográfica envolvida. Ao norte, elas precedem as estruturas $F_{2}$ (descritas a seguir) enquanto ao sul elas coliocam os metassedimentos em contato tectônico com a seqüência molássica, na qual essas estruturas são pouco ou não desenvolvidas. Esta falha é caracterizada por intensa brechação, cataclase e formação de um material preenchendo fraturas, similar a pseudotaquilito.

$F_{2}$ : Como estruturas tardias ocorrem bandas e dobras kink nos metapelitos, e crenulação nestes e nos metacarbonatos. Sua freqüência é maior ao norte do Rio Vaza Barris. O mergulho da clivagem $S_{2}$ é subvertical ou forte para o sul, essencialmente subparalelo ou em pequeno ângulo em relação ao de $S_{1}$. Variações nas atitudes de $S_{1}$, acompanhando modificaçōes no mergulho $S_{0}$, sugerem a atuação tardia de ondulações suaves como parte desse conjunto de estruturas. Clivagem de fratura tardia é também desenvolvida nos metapelitos, num padrão losangular cuja bissetriz. corresponde a $S_{1}$. A lineação $L_{2}$ reúne eixos de kinks e microcrenulações, e interseções de planos- $S$, mergulhando suave para leste. Nas proximidades da falha que delimita ao norte este domínio, ocorrem kinks com plano axial sub-horizontal e eixo mergulhando suave para NE-NNE, constituindo com os anteriores um sistema conjugado relacionado à compressão de norte para sul.

$F_{3}$ : Caracterizado por dobramentos com eixos de caimento médio $s$ forte para WNW (mais que $45^{\circ}$ ) e plano axial de mergulho forte para NNE (mais que $80^{\circ}$ ). São dobras fechadas a abertas, classe 1C, com charneira angular e mesmo de estilo kink. Estão associadas a zonas de cisalhamento WNW-ESE, com movimento transcorrente dextro dominante, algumas podendo representar reativação das falhas inversas já descritas. Dobras macroscópicas $F_{3}$ ainda não foram comprovadas, mas os trands ondulados nos mapas de Silva Filho et al. (1977), caso não constituam fechamentos $F_{1}$, podem ser examinados neste sentido. Ao contrário de $F_{1}$, pervasivo na região, as estruturas $F_{3}$ são localizadas a domínios lineares. 
O SEGMENTO NORTE: O GRUPO MACU. $R U R E$ Este domínio tem uma estrutura complexa, caracterizada pela superposição de fases de deformação e padrões de interferência. A Fig. 3 ilustra esse estilo estrutural.

\begin{tabular}{|c|c|c|}
\hline FASE & ESTRUTURAS & 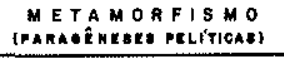 \\
\hline$F_{2} / M_{1}$ & $\sum_{\infty}^{\infty} \infty_{s_{2}}^{s-1}$ & $\begin{array}{l}\text { SERIC + CLOR } \pm \text { BIOT } \\
\text { B:OT + GRAN } \\
\text { BIOT + GRAN + ESTAUR } \\
\text { BIOT + GRAN + SIL } \\
\text { MIGMATIZAÇĀO }\end{array}$ \\
\hline$F_{2} / M_{2}$ & 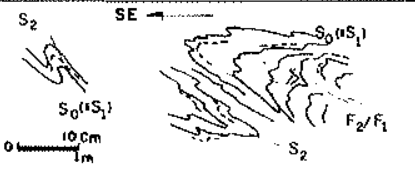 & $\begin{array}{l}\text { MICA ERANCA + CLOR } \\
\text { BIOT + CIAN + MICA BRANCA } \\
\text { BIOT + ANDALUZ }\end{array}$ \\
\hline$F_{3} / M_{3}$ & 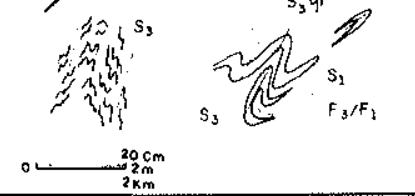 & $\begin{array}{l}\text { MICA BRANCA + OPACOS } \\
\text { MICA BRANCA + CIAN }\end{array}$ \\
\hline
\end{tabular}

Figura 3 - Estruturas e metamorfismo no segmento norte da Faixa Sergipana

$F_{1}$ : Representado por dobras isoclinais a apertadas,

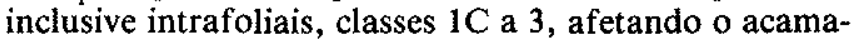
mento $\left(F_{\mathrm{o}}\right)$. Este pode ser reconhecido, em diversos exemplos na parte de grau mais baixo do segmento, pela ocorrência de estratifícação rítmica e gradual em metapelitos e metagrauvacas. Em áreas menos deformadas nos eventos posteriores, a atitude suave da foliação de plano axial indica um estilo próximo ao recumbente, com vergência sul. Os eixos também possuem mergulhos suaves, porém variáveis, em direção aos quadrantes NW ou SE. Relaçðes $S_{0} / S_{1}$ e minidobras $F_{1}$ permitem localizar macroestruturas, sendo provável a ocorrência de nappes neste tipo de deformação. $O$ estilo das minidobras $F_{1}$ e o ângulo entre $S_{0}$ e $S_{1}$ variam entre os flancos e as regióes de charneira. Nos flancos, temos dobras infrafoliais e isoclinais, $S_{1}$ é praticamente coincidente com $S_{0}$ e este é transposto e realçado por diferenciação metamórfica. Nas charneiras, $S_{0}$ e $S_{1}$ se cruzam em ângulo forte, o primeiro subvertical, e as minidobras são assimétricas ou do tipo $M$.

$S_{1}$ é uma xistosidade de biotita e/ou muscovita, às vezes substituídas por clorita/sericita nas regioes de grau mais baixo. São comuns os veios de quartzo paralelos a $S_{1}$, ou afetados por $F_{1}$, representando segregaçðes precoces ou contemporâneas ao dobramento, e indicando.um caráter progressivo de $F_{1}$. Esta última característica é também refletida na boudinage desses veios paralelos a $S_{1}$, a seguir dobrados por reativação do cisalhamento ao longo de $S_{1}, L_{1}$ inclui um rodding muito penetrativo, lineaçðes minerais (anfibólio, sillimani- ta) e interseç̃̃es $S_{0} / S_{1}$, além dos eixos de minidobras $\left(B_{1}\right)$.

No metaconglomerado de Gracho Cardoso, em muitos casos a fábrica $F_{1}$ pode ser traçada sem interrupção dos fragmentos à matriz. A deformação presente nos seixos e blocos é função de sua posição espacial (orientação de $S_{0}$ ) a respeito de $S_{1}$, desenvolvendo-se dobramentos nos casos em que esta relação é perpendicular ou obliqua. Por outro lado, alguns fragmentos exibem fábricas sem continuidade com a matriz, indicando que a deformação precedeu após a deposição daquele pacote. Como o material dos fragmentos é muito anisotrópico, torna-se difícil sua utilização como indicador da deformação finita.

A forte deformação e metamorfismo na zona alagoana dificulta muitas vezes a separação entre as supracrustais e o embasamento. Assim é que muitos gnaisses biotíticos e quartzo-feldspáticos, derivados da recristalização das supracrustais, foram incluídos no embasamento sem que haja uma descontinuidade de suas estruturas. Nesta região, o embasamento, onde efetivamente caracterizado, está representado por gnaisses e migmatitos, em fácies anfibolito alto ou mesmo granulito. As estruturas $F_{1}$ podem ser reconhecidas nos mesmos, sendo bem desenvolvidas especialmente próximo ao contato. É possivel observar, então, que nessas rochas $F_{1}$ deforma estruturas anteriores - bandeamento gnáissico-migmatítico, dobras isoclinais e mesmo padroes de interferência tipo domos e cogumelos (Fig. 4).

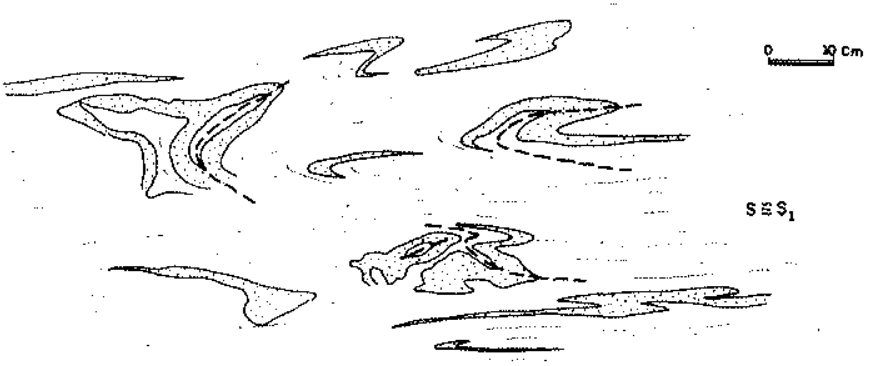

Figura 4 - Gnaisse migmatítico (neossomas pontilhados) do embasamento. Dobras correlacionáveis às $F_{\text {, nas supracrustais }}$ possuem uma foliação de biotita $\left(S_{1}\right)$ e deformam uma fábrica gnáissica $(S)$, dobras e padrôes de interferência mais antigos (planos axiais tracejados). Baseado em afloramentos ao norte de Belo Monte (AL)

$F_{2}:$ Caracterizado por dobras fechadas, inclinadas a invertidas, classe 1C. O plano axial tem direção NE-SW e mergulhos suaves a médios para NW $\left(15^{\circ}-65^{\circ}\right)$, os valores mais fracos presentes na região alagoana da faixa. Os eixos têm caimento suave a médio $\left(20^{\circ}-30^{\circ}\right)$ para NE-ENE.

A foliação $S_{2}$ é uma xistosidade de biotita ou muscovita enquanto $L_{2}$ inclui interseçðes de planos- $S\left(S_{2} / S_{1}\right.$ e $\left.S_{2} / S_{\mathrm{o}}\right)$ e eixos de minidobras $\left(B_{2}\right)$. Localmente, foram observadas crenulaçðes associadas a esta fase. 
$F_{2}$ afeta $S_{0}, S_{1}$ e $L_{1}$, dobrando estruturas. Em escala meso e macro, săo conhecidos padrões de interferência tipo 2 e $1 / 2$ (cogumelos, domos) com as dobras $F_{1}$.

$F_{3}$ : Caracterizado por dobras abertas a fechadas, inclinadas a invertidas, classe $1 \mathrm{C}$ a $1 \mathrm{~B}$. $O$ plano axial tem mergulho médio a forte $\left(50^{\circ}-70^{\circ}\right)$ para $\mathrm{SW}$, e eixo cai suave $\left(10^{\circ}-15^{\circ}\right)$ para WNW ou ESE.

A foliação $S_{3}$ é uma xistosidade com muscovita \pm clorita, ou biotita, e localmente um bandeamento alternando quartzo-clorita. $L_{3}$ inclui eixos de minidobras $\left(B_{3}\right)$, interseçőes de planos- $S\left(S_{3} / S_{\mathrm{o}}\right.$ e $S_{3} / S_{1}$ são vistas mais comumente) e minerais (clorita).

A interferência $F_{3} / F_{1}$ produz padróes tipo 3 (coaxiais), mais facilmente percebidos na escala de afloramento. Com $F_{2}$ é obtido um padrão intermediário 1/2 (domo assimétrico, cogumelo). Neste último caso, um exemplo macroscópico é à bacia-cogumelo de Nossa Senhora de Lourdes, a NE de Itabi (SE). Esta é uma estrutura complexa e a superposição $F_{3} / F_{2}$ já atuou sobre niveis quartzíticos intercalados em micaxistos e repetidos isoclinaimente pela fase $F_{1}$ (Fig. 5).

As dobras $F_{3}$ evoluem a empurrões, secionando o flanco invertido das estruturas. Brito Neves et al. (op. cit.) reportam uma estrutura desse tipo a norte de $\mathrm{Pal}$ meira dos Índios (AL). $F_{3}$ é penetrativo em toda a região.

$F_{4}$ : Está representado por clivagem de crenulação com mergulho forte para o norte e por king bands com eixo e foliaçåo subverticais, os últimos associados a zonas transcorrentes. Sua ocorrência parece localizada.

\section{O METAMORFISMO}

\section{O SEGMENTO SUL: OS GRUPOS MIABA E VAZA}

$B A R R I S$ Este segmento apresenta-se com baixo grau de metamorfismo e a granulometria fina dos minerais dificulta seu estudo ao microscópio. Na região mais setentrional do segmento (Mocambo), por exemplo, não é possivel discernir, ao microscópio, o crescimento de minerais ao longo da clivagem.

Mais ao sul, próximo a Simão Dias, filitos exibem sericita e clorita recristalizadas, contornando os grãos de quartzo. Em algumas rochas, e associado à clorita, aparece o estilpnomelano, que foi o último mineral a cristalizar. $\mathrm{O}$ aparecimento do estilpnomelano coincide aproximadamente com a transforrnação da caulinita em pirofilita, que se faz em torno de $350^{\circ} \mathrm{C}$, o início da fácies xisto verde. Por outro lado, o limite superior de estabilidade corresponderia ao aprecimento da biotita, aproximadamente a $440^{\circ} \mathrm{C}$, na transição para o grau mais alto da fácies xisto verde. $O$ estilpnomelano é estável tanto no mertamorfismo de pressőes baixas como no de pressoes intermediárias, embora seja mais freqüente neste último (Winkler, 1977).

Nas rochas carbonatadas, e principalmente em descontinuidades estruturais, anotam-se processos de recristalização metamórfica relacionáveis à introdução de fluidos no sistema. Onde a calcita está recristalizada em grăos maiores, podem-se encontrar quartzo, hidróxido de Ferro e, às vezes, talco. $O$ talco aparece com a desestabilização da dolomita ou calcita magnesiana em presença de quartzo introduzido no sistema. A temperatura dessa transformação depende da composição da fase fluida, notadamente a proporção $\mathrm{CO}_{2}-\mathrm{H}_{2} \mathrm{O}$. Como o talco aparece em fissuraçoes por onde circularam os fluidos transportando $\mathrm{SiO}_{2}$, pode-se imaginar que neste caso $\mathbf{P}_{\mathrm{H}_{2} \mathrm{O}} \mathbf{P}_{\mathrm{CO}_{2}}$, e desta maneira este mineral poderia aparecer entre 300 e $400^{\circ} \mathrm{C}$ e 1 a $3 \mathrm{~kb}$.

Em conclusão, o metamorfismo do segmento sul evolui da diagênese ou fácies prehnita-pumpelyita à fácies xisto verde, caracterizada pela presença de estilpnomelano ou talco (Fig. 2). Não existem evidências de polimetamorfismo. É possível que o aumento de grau se faça de norte para sul. Se confirmada, esta feição pode estar relacionada com a estrutura imbricada proposta, na qual as fatias de empurrão mais profundas e assim, sob condições de pressão e temperatura, estariam ao sul. Isto também sugere que o metamorfismo é sin a tardi-deformativo. Quanto ao tipo bárico, este deve ser de pressőes intermediárias.

O SEGMENTO NORTE: O GRUPO MACU$R U R E$ : $\quad$ Em correspondência à complexidade gerada por três fases de dobramentos, as paragêneses minerais nestas rochas também evoluíram ao longo de diferentes eventos de recristalização metamórfica (Fig. 3). O estudo dos xistos aluminosos numa seção do sul para o norte permite caracterizar preliminarmente essa evolução.

Mais ao sul, próximo a Feira Nova (SE), no que corresponde à zona da granada, de Silva Filho et al. (op. cit.), a xistosidade principal nas rochas $\left(S_{3}\right.$ é definida por mica branca associada a óxidos ou hidróxidos de ferro. A mica faz a separação de micrólitons, no interior dos quais constatam-se sericita e clorita, subparalelas ou encurvadas a respeito do plano- $S$ referido. Esses dois últimos minerais são interpretados como relíquias de um primeiro evento de recristalização na rocha $\left(M_{1}\right)$, nas fácies prehnita-pumpelyita ou xisto verde. A mica branca deve marcar um outro evento, provavelmente em fácies xisto verde.

Ao norte de Itabi (SE), a paragênese granada-biotita é a mais antiga reconhecida na lâmina, sendo a granada ligeiramente helicítica com a biotita. Esta última é deformada e ambas são porfiroblásticas. Uma xistosidade penetrativa $\left(S_{2}\right)$ é definida por clorita e uma mica branca pequena, desviando-se em torno dos porfiroblastos mais antigos. Por fim, existe uma segunda mica branca, com dimensões maiores porém em menor quantidade, oblíqua de pelo menos $10^{\circ}$ em relação ao plano $S_{2}$. Em resumo, pode ser reconhecido um primeiro evento de metamorfismo $\left(M_{1}\right)$, em fácies xisto verde ou anfibolito, responsável pela paragênese biotita-granada. Um segundo evento $\left(M_{2}\right)$, cuja mineralogia define a xistosidade mais importante da rocha, foi das fácies xistó verde. Por fim, um terceiro evento $\left(M_{3}\right)$, de fácies similar mas um tipo bárico lalvez diferente, a depender da composição da mica branca.

$\mathrm{Na}$ regiåo de Traipu (AL), correspondente à zona da estaurolita-cianita de Silva Filho et. al. (op. cit.), puderam ser observadas, numa mesma amostra, estaurolita, granada, cianita, biotita e mica branca, além do quartzo e opacos. O primeiro evento de metamorfismo é responsável pela recristalização da granada, biotita I e estaurolita, sendo assim da fácies anfibolito. Um segundo 


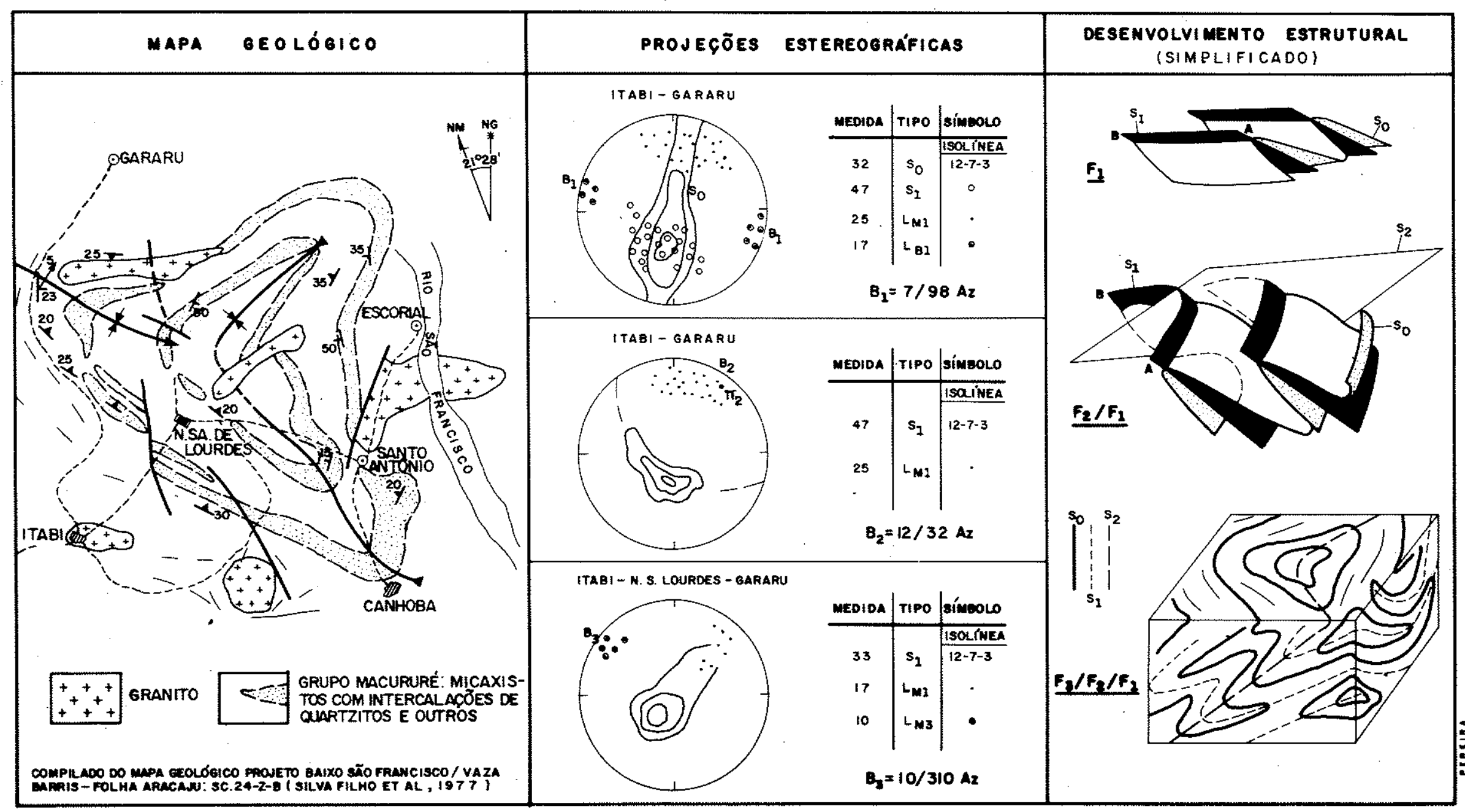


equilíbrio metamórfico $\left(M_{2}\right)$ é definido pela associação cianita-biotita II. Esta mica é desviada em torno das granadas que, junto com a biotita I e a estaurolita, estão incluídas pela cianita (Fig. 6a). A xistosidade principal da rocha, definida por mica branca associada a opacos, é desviada em torno dos porfiroblastos de cianita. Todavia, este mineral mostra um sobrecrescimento durante um último metamórfico $\left(M_{3}\right)$, inclusive englobando os opacos provenientes da transformação da biotita para mica branca (mais opacos). Pode-se confirmar assim a existência de um segundo evento metamórfico $\left(M_{2}\right)$, do grau mais alto da fácies xisto verde e do tipo de pressão intermediária, caracterizado pela associação biotita II-cianita. O terceiro evento $\left(M_{3}\right)$ é também de pressão intermediária, mas localizado abaixo da isógrada da biotita.

A região de Batalha (AL) situa-se na zona da sillimanita, de Silva Filho et al. (op. cit.), onde também aparecem os migmatitos (isógrada de anatexia). A sillimanita foi encontrada numa amostra que ainda continha biotita, opacos, mica branca, granada, andaluzita e quartzo. Em campo e lâmina, observam-se faixas de sillimanita $\left(L_{1}\right)$ dobradas com o plano axial correspondente a $S_{2}$. Essa sillimanita coexiste com granada e biotita I, formando a paragênese de um primeiro metamorfismo $\left(M_{1}\right)$, em fácies anfibolito. As condições de metamorfismo de uma segunda fase $\left(M_{2}\right)$ são indicadas pela transformação da sillimanita em andaluzița, esta última alongada no plano $S_{2}$, junto com recristalização de biotita (biotita II), agora englobando a sillimanita (Fig. $6 b$ ), e rotacionando as granadas. Da mesma maneira que para a região de Traipu, o terceiro evento $\left(M_{3}\right)$ é caracterizado pela transformação da biotita em mica branca, que poderia corresponder a um aumento de pressão caso fosse comprovado um caráter fengítico para a mesma.
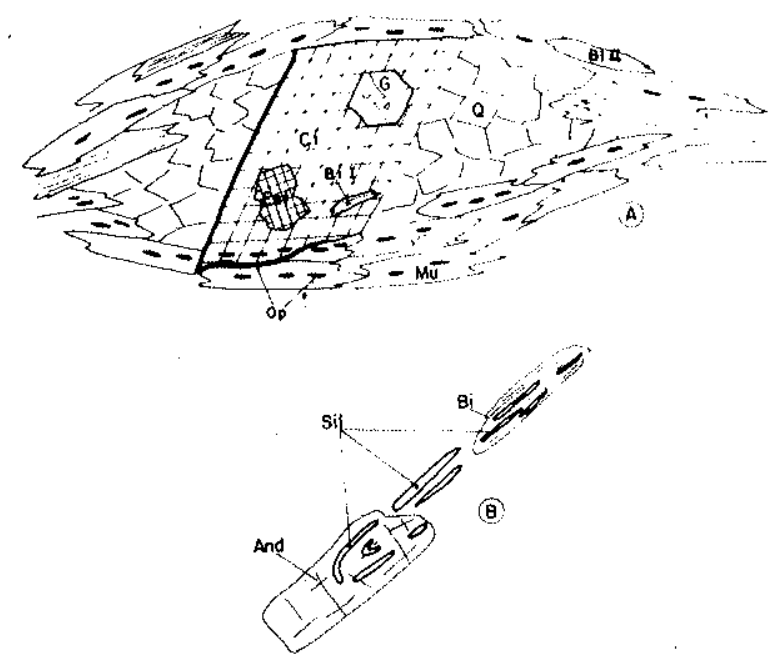

Figura 6 - Relações microestruturais evidenciando superposição de diferentes paragêneses metamórficas. As letras significam: Q, quartzo; And, andaluzita; Bi, biotita; Mu, muscovita; $\mathrm{G}$, granada; Est, estaurolita; $\mathrm{Ci}$, cianita; $\mathrm{Op}$, opacos
Concluindo, pode-se distinguir no segmento norte um primeiro evento metamórfico, $M_{1}$, cronologicamente relacionável a $F_{1}$, evoluindo do sul para o norte, da fácies xisto verde à parte de grau mais elevado da fácies anfibolito. Sucedem-se as zonas da clorita, biotita-granada; estaurolita, sillimanita e migmatitos.

Um segundo evento, $M_{2}$, é relacionável a $F_{2}$. A sillimanita de $M_{1}$ se transforma em andaluzita, cianita aparece na zona da estaurolita de $M_{1}$, e clorita e mica branca desenvolvem-se na antiga zona da biotita-granada. Este evento é assim de grau mais baixo e provavelmente envolve um aumento de pressão, como é sugerido pela cristalização da cianita sucedendo à estaurolita (o inverso ocorre nas séries de metamorfismo progressivo de pressðes intermediárias). Se a cianita tornou-se estável apenas em $M_{2}$, o evento anterior $\left(M_{1}\right)$ deveria caracterizar-se por andaluzita - a qual não teria sido identificada nas amostras estudadas da zona correspondente devido a uma composição não favorável das mesmas, ou o Al necessário para formá-la estaria contido em outros minerais, como uma biotita aluminosa. A presença no evento metamórfico $M_{2}$, da cianita antecedendo à andaIuzita com o aumento de grau, implica para o mesmo um gradiente geotérmico próximo (e interceptando) à curva de transformação andaluzita-cianita, a qual corresponde aproximadamente a $30^{\circ} \mathrm{C} / \mathrm{km}$. Como a passagem de $M_{1}$ a $M_{2}$ parece ter envolvido aumento de pressão, deduz-se que $M_{1}$ deveria ser do tipo pressões baixas. Este ponto é também apoiado pela ocorrência de anatexia na zona da sillimanita enquanto no metamorfismo de pressōes médias esta já pode ocorrer na zona da cianita. A seqüência observada para $M_{1}$ corresponde também àquela descrita por H. L. James (in Winkler, $o p$. cit.) em Michigan, onde domos termais associados a intrusões graníticas puderam ser delineados.

$\mathrm{Na}$ Fig. 7 procurou-se esboçar, de maneira aproximada, a evolução dos gradientes geotérmicos. Neste diagrama $\mathrm{P}_{\mathrm{H}_{2}} \mathrm{O}-\mathrm{T}$, a interseção das linhas caracterizando os eventos $M_{1}$ e $M_{2}$ na zona anatética indica que as condições de pressão e temperatura do metamorfismo poderiam ter sido idênticas para rochas situadas no extremo norte da faixa. Desta maneira, associaçðes minerais de $M_{1}$ persistiriam estáveis em $M_{2}$.

Por fim, o evento $M_{3}$ é caracterizado por mica branca e cianita. Esta última assinala metamorfismo do tipo pressão intermediária e, logicamente, a mica branca teria caráter fengítico. A ausência de andaluzita deve implicar um gradiente de pressão e temperatura ligeiramente mais fraco que o de $M_{2}$. Na maioria dos casos, a mica branca está associada a opacos, provavelmente magnetita. Sua origem estaria ligada à desestabilização da biotita, seja de $M_{1}$ ou $M_{2}$, segundo reação do tipo

$$
\begin{aligned}
3 \mathrm{~K}_{2} \mathrm{O}\left(\mathrm{FeO}_{0,9} \mathrm{MgO}_{0,1}\right)_{5}\left(\mathrm{Al}_{2} \mathrm{O}_{3}\right)\left(\mathrm{SiO}_{2}\right)_{5}\left(\mathrm{H}_{2} \mathrm{O}\right)_{2} & +6 \mathrm{SiO}_{2}+2 \mathrm{O}_{2} \rightleftharpoons \\
\text { 3Siderofilita (biot. aluminosa) } & +6 \mathrm{Qz}+2 \mathrm{O}_{2} \rightleftharpoons \\
3 \mathrm{~K}_{2} \mathrm{O}\left(\mathrm{FeO}_{0,5} \mathrm{MgO}_{0,5}\right)\left(\mathrm{Al}_{2} \mathrm{O}_{3}\right)_{2}\left(\mathrm{SiO}_{2}\right)_{7}\left(\mathrm{H}_{2} \mathrm{O}\right)_{2} & +4 \mathrm{Fe}_{3} \mathrm{O}_{4} \\
\text { 3Fengita } & +4 \mathrm{Magnetita}^{2}
\end{aligned}
$$

Como podemos ver, esta reação não corresponde a uma desidratação mas a uma adaptação mineralógica sob condiçóes de pressão estática mais elevada, ligada a uma oxidação do meio. 


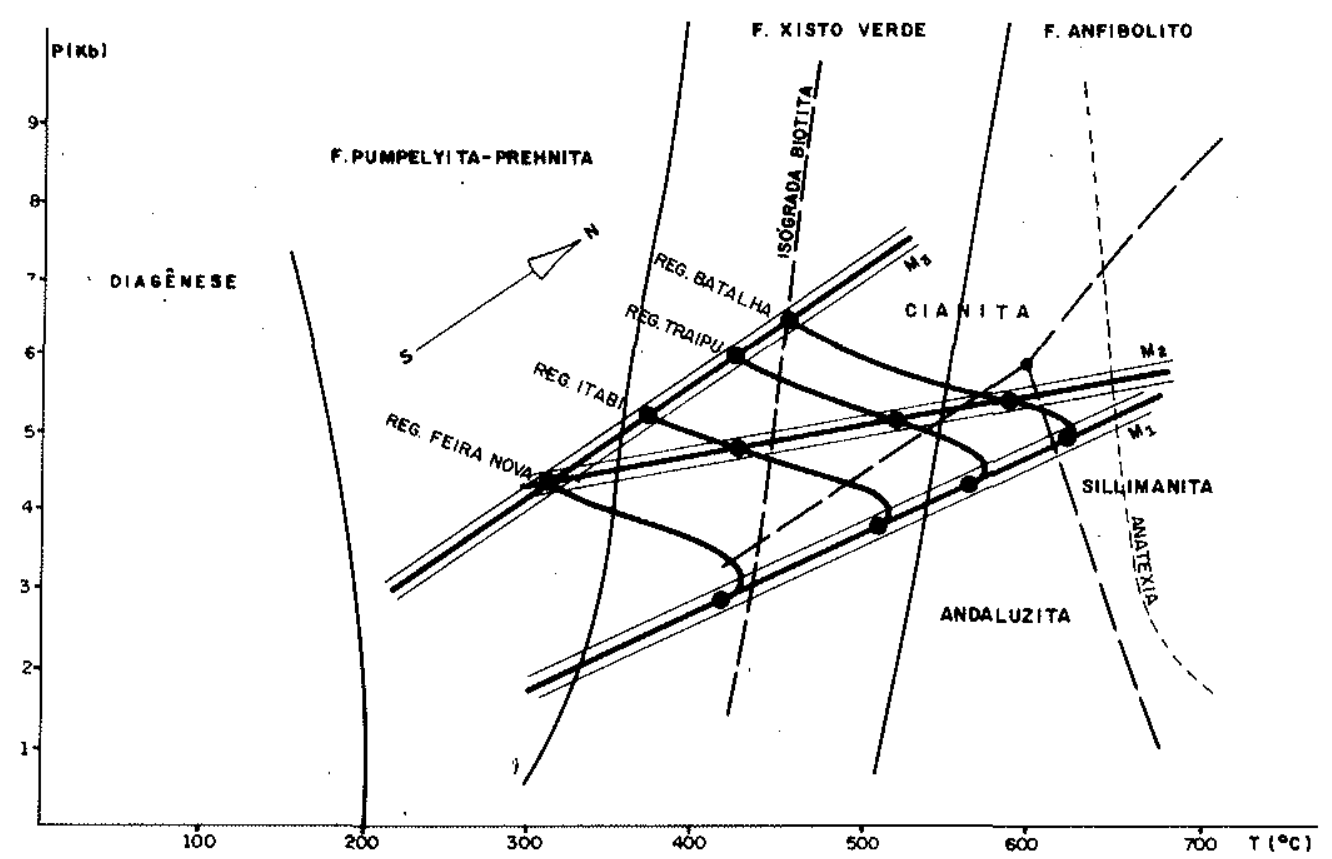

Figura 7 - Diagrama P-T esquemático para o segmento norte da Faixa Sergipana

$\mathrm{Na}$ região mais ao sul (Feira Nova), as linhas caracterizando $M_{2}$ e $M_{3}$ novamente se interceptam (Fig. 7). Isso pode explicar por que nesta região são encontradas apenas duas paragêneses superpostas, as condiçóes de pressão e temperatura sendo mantidas similares durante aqueles dois eventos. Finalmente, o conjunto das três linhas sugere uma queda progressiva no gradiente geotérmico da região.

\section{RELAÇÕES ENTRE OS SEGMENTOS NORTE E} SUL DA FAIXA DOBRADA O contato entre os dois segmentos da faixa é feito por falhas de empurrão (ver mapas de Silva Filho et al., op. cit.), o que dificulta correlaçðes como a proposta. Dos perfis examinados, o mais bem exposto e onde as relaçðes são mais claras vai de Paripiranga a Coronel João Sá (BA), via povoado de Maritá. A falha de empurrão mapeada é comprovada por zona cataclástica. Ao sul da falha, o Grupo Vaza Barris é representado por metarcósios, metagrauvacas e ardósias. A foliação $S_{1}$, agora representada por $\left(S_{1}\right)_{S}$, mergulha em torno de $70^{\circ}$ a $80^{\circ}$ para $200 \pm 10^{\circ} \mathrm{Az}$, sendo plano axial de dobrás apertadas ou fechadas no contato; ficando mais abertas ao sul $-\left(F_{1}\right)_{\mathrm{S}} \cdot\left(L_{1}\right)_{\mathrm{S}}$ varia de $25^{\circ}-35^{\circ} / 300 \pm 5^{\circ} \mathrm{Az}$. Estruturas de crenulação tềm orientação similar e kinks formam um sistema com plano axial sub-horizontal conjugado.

Ao norte da falha o Grupo Macururé é representado por micaxistos de baixo e médio grau. São conspícuas minidobras fechadas e apertadas, similares ou em estilo kink, com plano axial mergulhando $70^{\circ}-75^{\circ} / 300$ $\pm 5^{\circ} \mathrm{Az}$. Essas dobras deformam uma xistosidade prévia bem como originam padrőes de interferência tipo 3 , devendo assim corresponderem às estruturas $F_{3}$ do domínio norte $-\left(F_{3}\right)_{\mathrm{N}}$, com o plano axial e eixos representando $\left(S_{3}\right)_{\mathrm{N}}$ e $\left(L_{3}\right)_{\mathrm{N}}$. Por outro lado, a xistosidade mais antiga é identificada como $\left(S_{1}\right)_{N}$, sendo freqüentes as intrafoliais $\left(F_{1}\right)_{\mathrm{N}^{*}}\left(S_{0}\right)_{\mathrm{S}}$ e $\left(S_{1}\right)_{\mathrm{N}}$ estão envolvidas em um mesmo macrodobramento $-\left(F_{1}\right)_{\mathrm{S}}$ ou $\left(F_{3}\right)_{\mathrm{N}}-$ com as minidobras e foliações comportando-se congruentemente nos dois domínios, sugerindo anticlinal/antiforme com foliação em leque ao sul do trecho aqui referido.

Duas possibilidades de correlação estrutural podem ser discutidas (Fig. 8). No primeiro caso, correlacionam-se as estruturas $\left(F_{1}\right)_{\mathrm{S}}$ com $\left(F_{1}\right)_{\mathrm{N}}$. Neste caso implica que a deformação do Grupo Vaza Barris é contemporânea à do Macururé e as estruturas maís novas deste último $\left(F_{2}\right.$ e $\left.F_{3}\right)$ não foram desenvolvidas ao sul. A diferença de estilos estruturais implica na deformação $F_{1}$ dobras subverticais ou inclinadas, mais abertas, evoluindo até crenulaçð̋es no sul versus dobras recumbentes mais apertadas ao norte - seria explicada pela justaposição tectônica das seqüências, com o empurrão do contato sendo posterior aos ciobramentos. A coincidência das atitudes de $\left(S_{1}\right)_{\mathrm{S}}$ e $\left(S_{3}\right)_{\mathrm{N}}$ fica creditada ao acaso.

A hipótese alternativa é equiparar as estruturas $\left(F_{1}\right)_{\mathrm{S}}$ $\operatorname{com}\left(F_{3}\right)_{\mathrm{N}}$, o que é apoiado pela flagrante correlação das atitudes e do estilo de dobramento, que afetaria $\left(S_{0}\right)_{\mathrm{S}}$ e $\left(S_{1}\right)_{\mathrm{N}}$. Neste caso, a deformação do 'Grupo Macururé seria mais antiga que a do Vaza Barris. $O$ falhamento no contato seria pré a $\sin -\left(F_{1}\right)_{\mathrm{S}}$, os estilos estruturais são compatíveis e as crenulaçōes diretamente correlacionáveis através do contato. Dobras mais abertas ao norte - $\left(F_{3}\right)_{\mathrm{N}}$ - seriam explicadas pela maior competência do Grupo Macururé, previamente deformado, em comparação ao Vaza Barris.

Embora este ponto deva continuar a ser examinado em pesquisas subseqüentes, as evidências atualmente disponíveis são favoráveis à aceitação da segunda hipótese.

A correlação dos eventos de metamorfismo é mais problemática. Todavià, nota-se que o metamorfismo monofásico do segmento sul, caracterizado por estilpnomelano e provável pressão intermediária, é mais dire- 


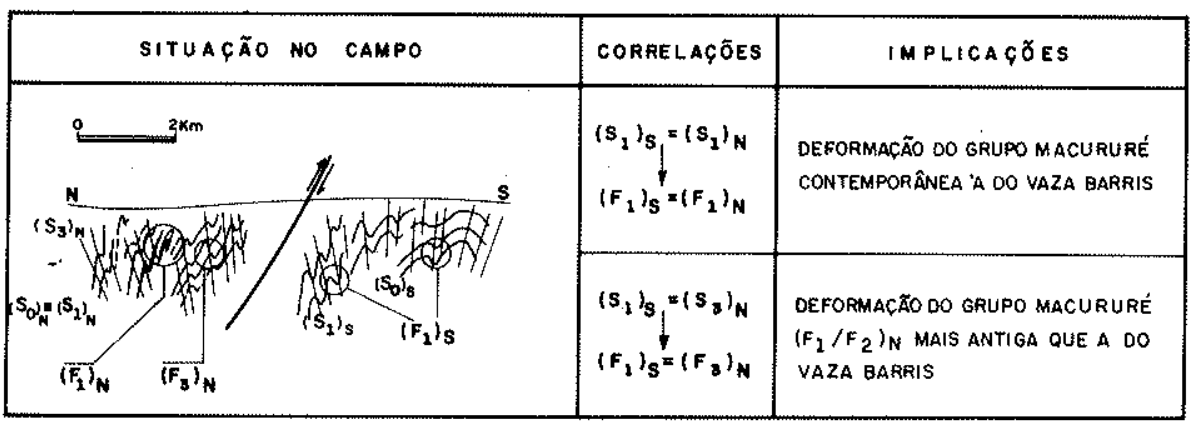

Figura 8 - Correlações estruturais esquemáticas entre os segmentos norte e sul da Faixa Sergipana

tamente comparável ao evento $M_{3}$ ao norte. Esta correlação apóia-se adicionalmente nos dados estruturais e sugere que o último evento de metamorfismo na margem NE do Craton São Francisco foi bastante regional e do tipo de pressões intermediárias, variando da fácies prehnita-pumpellyita à fácies xisto verde ou anfibolito baixo.

\section{CONCLUSÕES E IMPLICAÇÕES QUANTO AO ARCABOUÇO GEOLÓGICO REGIONAL OS dados} apresentados apóiam a idéia de que o segmento norte da faixa dobrada, representado pelo Grupo Macururé, já havia sofrido dois episódios de deformação e metamorfismo, anteriores aos eventos desse tipo nos grupos Miaba e Vaza Barris. Os eventos $\left(F_{1}\right)_{\mathrm{N}}$ e $\left(F_{2}\right)_{\mathrm{N}}$ aumentam em intensidade no sentido norte. $O$ primeiro tem vergência sul e o segundo, SE, caracterizando um dobramento cruzado. Ambos foram acompanhados por eventos de metamorfismo, cujo grau aumenta para o norte. $O$ mais antigo $\left(M_{1}\right)_{\mathrm{N}}$ atingiu a isógrada da sillimanita e migmatização enquanto o segundo $\left(M_{2}\right)$ possui andaluzita $\mathrm{e}$ cianita.

Os eventos $\left(F_{3}\right)_{\mathrm{N}}$ e $\left(F_{1}\right)_{\mathrm{S}}$ podem ser correlacionados e, neste caso, uma vergência centrífuga, conforme proposto por Brito Neves et al. (op. cit.), fica comprovada. A intensidade da deformação pode diminuir em direção ao centro da faixa mas ơ dados não são conclusivos a esse respeito. $\mathrm{O}$ metamorfismo $\left(\mathrm{M}_{3}\right)_{\mathrm{N}}$ parece corresponder ao metamorfismo monofásico ao sul, $\left(M_{1}\right)_{\mathrm{S}}$, em regime de pressões intermediárias.

O zoneamento geotectônico atualmente aceito para esta faixa é compatível com ambas as hipóteses de correlação discutidas. Todavia, devemos ressaltar que a hipótese favorecida permite considerar dois tipos de relacionamento entre os grupos Macururé, de um lado, e Miaba-Vaza Barris, de outro. Em primeiro lugar, a história deposicional dos mesmos pode ser aproximadamente contemporânea, opinião preferida na literatura. A diminuição de grau metamórfico e a ocorrência de estruturas mais simples na direção sul, no contexto do zoneamento geotectônico, tornam esta hipótese atraente. No segundo caso, o Grupo Macururé representaria um embasamento para a seqüência Miaba-Vaza Barris.

Dados radiométricos e correlações regionais são requeridos para o teste dessas possibilidades. As dataçðes atualmente disponíveis na região são ainda insuficientes mas podem ser examinadas a esse respeito. Idades no âmbito do Ciclo Brasiliano - $600 \pm 50$ m.a. - são encontradas em rochas metamórficas e granitos intrusivos (maciços diapíricos pouco deformados, equivalentes ao tipo $G_{3}$ da região de Seridó; ver Jardim de Sá et. al., (inédito), sendo do tipo $\mathrm{K} / \mathrm{Ar}$ em micas e $\mathrm{Rb} / \mathrm{Sr}$ convencional em rocha total ou biotita. Esses dados normalmente indicam o resfriamento e ó levantamento regional ao final da orogênese Brasiliana no Nordeste (McReath e Jardim de Sá, 1979), sendo mais provavelmente correlacionáveis ao evento $F_{3} / M_{3}$ no Grupo Macururé, e $F_{1} / M_{1}$ no Miaba-Vaza Barris. Em alagoas, seis idades $\mathrm{Rb} / \mathrm{Sr}$ convencional em rocha total (novamente, idades mínimas de um evento termal) foram reportadas por Brito Neves e Cordani (1973) como referentes ao embasamento da faixa (o "Maciço Pernambuco-Alagoas"). Trata-se de datações em rochas graníticas e granitognáissicas, variando entre 870 e 1340 m.a., assim nitidamente pré-brasilianas. De acordo com o mapeamento de Silva Filho et. al. (1977), todavia, essas amostras situam-se em plena área dos xistos e gnaisses Macururé ou provêem de rochas graníticas pré-brasilianas intrusivas nas supracrustais. Similar proveniência pode ser admitida pelo menos para parte das amostras recentemente datadas por Brito Neves (com. escr., 1978) - augen gnaisses e xistos, nas regizes de Jirau do Ponciano e Palmeira dos Indios (AL), com idades convencionais ca. 2,0 e 0,8 b.a., respectivamente. A interpretação prévia de supracrustais neo-proterozóicas para o Grupo Macururé fica assim aberta a críticas, e trabalhos em maior detalhe tornam-se necessários.

Em termos de correlações regionais, o Grupo Macururé pode ser equiparado, em termos de litologia e estilo de deformação, às sequeências do Seridó (RN-PB) e Salgueiro-Cachoeirinha/Riacho do Pontal (PB-PE-PI). A possibilidade de uma idade pré-brasiliana tem sido considerada para a primeira (Jardim de Sá, 1978; e McReath e Jardim de Sá, op. cit.) e recentemente comprovada para esses últimos (Jardim de Sá e Hackspacher, 1980; ver também a carta geológica ao milionésimo da Bahia - Inda e Barbosa, 1978).

O Grupo Vaza Barris tem sido atribuído ao Proterozóico superior, com base em correlações litológicas com os grupos Una e Bambuí (ver discussão em Bruni, $o p$. cit.). É difícil julgar o valor dessa correlação no presente ainda que a semelhança seja realçada. Estudos de estromatólitos e microfósseis nos carbonatos Olhos d'Água poderiam ajudar a esse respeito. Infelizmente, as espécies conhecidas até o presente não permitem posicionar cronologicamente esses calcários (Srivastava, inéd.). Allard (1969), após estudos de campo no Brasil e na África, correlacionou a seqüência sergipana com a 
Série Ndjolé, no Gabão, embora notando a ausência, nesta última, dos carbonatos e metagrauvacas seixosas características. Na verdade, a descrição fornecida parece mais adequada ao Grupo Mucururé, inclusive com aumento de grau e transição dos filitos a "cornubianitos com biotita e granada". A Série Ndjolé tem idade mínima ca. 1,8 b.a. (Weber, 1968) e é capeada em discordância pelas séries Schisto-calcaire e Schisto-gréseuse, de idade Proterozóico superior, e estendendo-se do Gabão a Angola. As descriçðes dessas últimas são mais diretamente comparáveis às do Miaba e Vaza Barris.

Brito Neves et al. (op. cit.) e Silva Filho et al. (op. cit.) apresentaram modelos de tectônica de placas para explicar o desenvolvimento desta faixa dobrada. Todavia, ainda não foram constatados ou comprovados, de um lado, os critérios-chave para um regime de placas, tais como metamorfismo de alta pressão, cinturões metamórficos emparelhados, mélanges, ofiolitos, etc. De outra parte, feiçðes propostas nos modelos citados entram em conflito com os dados que apresentamos, já que nos mesmos é admitida a atuação de uma zona de subducção mergulhando para o sul, o que implicaria que a deformação do Vaza Barris fosse polifásica e mais antiga que a do Macururé, exatamente o oposto do que é indicado pelas seqüências de estruturas e metamorfismo. Adicionalmente,"estudos subseqüentes de Geofísica também descartam os modelos de placas (Rand et. al., 1980).
Em conclusão, apresentamos como hipótese favorecida a correlação do Grupo Macururé com outras seqüências policíclicas do nordeste, tipo Seridó e Riacho do Pontal, de provável idade eo-proterozóica. Por outro lado, o segmento sul, monocíclico, tem correlação mais provável com o Grupo Bambuí, sendo assim de idade neo-proterozóica. Sua evolução parece ensiálica, não havendo comprovação de abertura oceânica e subducção até o presente. É ressaltada a semelhança de seu desenvolvimento com o da faixa Tiririne, no oeste do Hoggar (Saara central; ver Bertrand et al., 1978). Um sulco ensiálico foi preenchido por uma sequência plataformal-turbidítica (com possíveis conglomerados glaciogênicos), que passa ao topo a fácies molássicas ( $c f$. grupos Miaba e Vaza Barris). Acima do Craton do leste do Saara, adjacente ( $c f$. Craton São Francisco), os sedimentos permaneceram pouco perturbados ( $c f$. Grupo Estância/formaçð̃es molássicas). A deformação é atribuída a um choque, sem prévia subducção, com empurrão de um embasamento pré-Pan-Africano (o qual é rejuvenescido e intrudido por granitos; $c f$. Grupo Macururé) sobre e fechando o sulco ensiálico.

Agradecimentos Os autores agradecem ao Dr. N. K. Srivastava, pelo auxílio em parte dos trabalhos de campo, e às críticas e sugestões do Dr. J. Wakefield, do Departamento de Geologia da UFRN, que revisou o artigo.

\section{BIBLIOGRAFIA}

ALLARD, G.O - 1969 - The Propiá geosyncline, a key tectonic element in the continental drift puzzle of the South Atlantic. Anais XXIII Congr. Bras. Geol., Salvador: $47-59$

ALMEIDA, F.F.M. - 1967 - - "Origem e evolução da plataforma brasileira" Dep. Nac. Prod. Min., Div. Geol. Min,, Bol. 241 : $36 \mathrm{pp}$.

BARBOSA, O. - 1970 - "Geologia econômica de parte da regiâo do Médio São Francisco". Dep. Nac. Prod. Min., Div. Fom. Prod. Min., Bol, 140: 98 pp.

BERTRAND, J.M.L., CABY, R., DUCROT, J., LANCELOT, J., MOUSSINE-POUCKINE, A e SAADALLAH, A. - 1978 - "The late Pan-African intracontinental fold belt of the Eastern Hoggar (Central Sahara, Algeria): geology, structural development, $\mathrm{U} / \mathrm{Pb}$ geochronology, tectonic implications for the Hoggar Shield". Precambrian Res. 7: 349-376.

BRITO NEVES, B.B. - - 1975 - "Regionalização Geotectônica do Precambriano Nordestino". Tese de Doutoramento, inst. Oeoc. USP: $198 \mathrm{pp}$

BRITO NEVES, B.B. e CORDANI, U.G. - 1973 - "Problemas geocronolbgicos do 'Geossinclinal Sergipano' e do seu embasamento". Anais $X X V I I$ Congr. Bras. Geol., Aracaju, 2: 67-76.

BRITO NEVES, B.B., SIAL, A.N. e BEURLEN, H. - 1977a - "O sistema de dobramentos sergipano - Análise do conhecimento". Anais Rev. Prep. Simp. Craton Săo Francisco e faixas marginais. Soc. Bras. Geol., Núcleo Bahia, Publ. Esp. 3: 369-391.

BRITO NEVES, B.B., SIAL, A.N. E ALBUQUERQUE, J.P.T. - $1976 b$ "Vergência centrífuga residual no sistema de dobramentos Sergipano". Rev. Bras. Geoc. 7 (2): 102-114.

BRUNI, M.A.L. - 1976 - Texto explicativo para a Carta Geologica do Brasil ao Milionésimo, Folha SC-24 Aracaju. Dep. Nac. Prod. Min., Brasília: 227 $\mathrm{pp}$.

ELTER, P. e TREVISAN, L. - 1973 - "Olitostromes in the tectonic evolution of the Northern Apennines", In "Gravity and Tectonics", de Jong, K.A. Scholten, R. (eds.), J. Wiley \& Sons: 175-188.

HUMPHREY, F.L. e ALLARD, G.O. - 1969 - "Geologia da área do Dómo de Itabaiana (Sergipe) e sua relação com a geologia do Geossinclinal de Propriá", Petrobrás, Cenpes, Doc. Téc. Pat.: $160 \mathrm{pp}$.

INDA, H.A.V. e BARBOSA, J.F. - 1978 - Texto explicativo para o Mapa Geológico do Estado da Bahia, Esc. 1:1 000 000. Sec. Minas Energia - BA, Coord. Prod. Min.: 137 pp.

JARDIM DE SÁ, E.F. - 1978 - "Revisăo preliminar sobre a "Faixa Dobrada do Serido' e eventuais correlatos no Nordeste". Rev. Ciência, UFRN, 1 (1): $77-83$.

JARDIM DE SÁ, E.F. e HACKSPACHER, P.C. - 1980 - "Reconhecimento estrutural na borda Noroeste do Cráton São Francisco". Anais XXXI Congr. Bras. Geol. 5: 2616-2625.
JARDIM DE SÁ, E.F., LEGRAND, J.M. e McREATH, I, - inéd, - "Estratigrafia" de rochas granitóides na região do Seridó (RN-PB), com base em critérios estruturais". Rev. Bras. Geoc. (submetido à)

JORDAN, H. - 1968 - "O Calcário Bambuí e o Grupo Canudos na região de Curaçá, Bahia", SUDENE, Dep. Rec. Nat., Div, Geol., Bol. Est. 4: 59.63.

JORDAN, H. - 1971 - "The late precambrian synclinorium of Curuçá (Brazil)". Geol. Jb. $6(88): 617.628$.

MCREATH, I. e JARDIM DE SÁ, E.F. - 1979 - Datações geocronológicas em rochas policiclicas: interpretação alternativa para os dados no Seridó (RN-PB). Atas IX Simp. Geol. Nordeste: 84-92.

MELLO, A.A., SIOUEIRA, L.P., CAVALCANTI, A.T., WANDERLEY, P.R.M., SALDANHA, L.A.R. e ROCHA, F.C. - 1977 - "Contribuição à geotectônica da região Nordeste do Brasil: área do rio Vasa-Barris e curso baixo do rio Săo Francisco". Bol. Miner, 5: 25-40.

MELLO, Z.F. - 1977 - "Consideraçðes tectono-petrológicas em sequências molássicas no Nordeste oriental do Brasil". Dissert. Mestrado, Univ. Fed. Pernambuco, Inst. Geoc.: 254 pp.

MELLO, Z.F. - 1978 - "Evoluçðes finais do Ciclo Brasiliano no Nordeste Oriental'. Anais XXX Congr. Bras, Geol., Recife, 6: 2438-2450.

RAND, H., SIAL, A.N, BRITO NEVES, B.B. e.MANSO, V.V. - $1980-$ "Gravimetric and magnetometric study of the late Precambrian Sergipe folding system; Northeast Brazil". Anais XXXI Congr. Bras., Geol., 5: $2700-2708$.

SANTOS, E.J, e SILVA FILHO, M.A. - 1975 - " "Ensaio interpretativo sobre a evoluçấo da Geossinclinal de Propriá, Nordeste do Brasil". Min. Metal. XXXIX (367): 3 22

SILVA FILHO, M.A. et al. $-1977-$ "Geologia da geossinclinal Sergipana e do seu embasamento, Projeto Baixo São Francisco/Vaza Barris, Relatório Final", Conv. DNPM/CPRM, vol, 1

SILVA FILHO, M.A., BONFIM, L.F.C. e SANTOS, R.A. - 1978 - "A geossinclinal sergipana: estratigrafia, estrutura e evolução". Anais XXX Congr. Bras. Geol., Recife; 6: 2464-2477.

SRIVASTAVA, N.K. - $1980-$ "Some remarks on the stromatolites of the groups Una(BA) and Vaza Barris(SE), Brazil". Manuscrito inédito.

WEBER , F - 1968 - "Une séric précambrienne du Gabon: te Francevillien. Sédimentologie, Géochimie, relations avec les gites minéraux associés", Mém. Serv. Carte géol. Als. Lorr. 28: 328 pp.

WINKLER, H.G.F. - 1977 - "Petrogênese das Rochas Metamórficas". Ed. Edgard Btücher Ltda.: $254 \mathrm{pp}$. 